\title{
Orbiniidae polychaetes (Polychaeta: Scolecida) from Coiba Island, eastern Pacific of Panama, with description of a new species
}

\author{
Eduardo López, Pedro Cladera \& Guillermo San Martín \\ Laboratorio de Biología Marina e Invertebrados; Departamento de Biología (Zoología); Universidad Autónoma de \\ Madrid. E-28049 Spain; Fax: +34 9149783 44; eduardo.lopez@uam.es
}

Received 22-V-2002. C Corrected 23-XI-2003. Accepted 09-VIII-2006.

\begin{abstract}
Santa Cruz and El Gambute, two mangrove systems with associated tidal flats, were sampled in Coiba National Park, Coiba Island, Pacific of Panama. At each site, two samplings were done at low, middle and high intertidal levels in February and November of 1997. A new orbiniid species were found: Orbinia oligopapillata n. sp. is characterized by having 15-16 thoracic chaetigers with four or five rows of uncini and up to three papilliform postchaetal processes on neuropodial lobes by the abdominal parapodia bearing flail-tipped neurochaetae, and by the presence on anterior-most abdominal chaetigers of interramal cirri and a low number of subpodial and stomach papillae. A specimen belonging to genus Leitoscoloplos Day, 1977 is described as "Leitoscoloplos sp.”, characterized by the lateral pouches on its abdominal chaetigers, a unique case for the family because these brooding structures have only been previously cited in two species of Scoloplos. Naineris sp. is characterized by the number of its thoracic chaetigers, branchiae, uncini and bilobed abdominal neuropodia with protruding aciculae. Rev. Biol. Trop. 54 (4): 1307-1318. Epub 2006 Dec. 15.
\end{abstract}

Key words: mangrove, tidal flats, Tropical Eastern Pacific, Orbiniidae, brooding polychaeta.

The Orbiniidae (Polychaeta: Scolecida) are burrowing polychaetes that can be found from low tidal to abyssal depths, acting in most cases as nonselective subsurface deposit feeders. The most important review of orbiniid systematics is by Hartman (1957), where all the genera known so far were redefined. Other important contributions to the knowledge of the family have been made by Pettibone (1957), Day (1977), Taylor (1984), Mackie (1987), Solís-Weiss and Fauchald (1989), Blake (1996) and LeónGonzález and Rodríguez (1996). However, the systematics of the family is still unclear and in some cases the boundaries between some genera are obscure, causing some close species to have been described within different genera. Blake (2000) performed a brief revision of the family where a new partition in subfamilies is proposed and some genera are erected or re-erected from subgeneric status.
Although limited, (each genus was represented only by type of species in the cladistic analysis, not considering intrageneric variability) this paper may be a very good starting point for a complete revision of the family. To date 16 species of Orbiniidae have been recorded from the tropical Eastern Pacific: Califia mexicana Hartman, 1957, Leitoscoloplos kerguelensis (McIntosh, 1885), L. panamensis (Monro, 1933), L. pugettensis (Pettibone, 1957), L. fragilis (Verrill, 1873), Leodamas mazatlanensis Fauchald, 1972, L. minutus López et al., 2003, L. ohlini Ehlers, 1901, L. platythoracicus López et al., 2003, L. rubra (Webster, 1879), Naineris laevigata (Grube, 1855), Orbinia bioretti (Fauvel, 1919), O. johnsoni (Moore, 1909), O. papillosa (Ehlers, 1907), Scoloplos acmeceps Chamberlin, 1919, and S. armiger (Müller, 1776) (Fauchald 1977, Salazar-Vallejo et al. 1988, López et al. 2002, 2003). 


\section{MATERIALS AND METHODS}

During 1996 and 1997 a research project aiming to characterize the marine benthic fauna of Coiba National Park was conducted (López et al. 1997, 2002, San Martín et al. 1997, Capa et al. 2001a,b). This park is located off the Pacific coast of Panama, between $7^{\circ} 10^{\prime}$ $7^{\circ} 53^{\prime} \mathrm{N}, 81^{\circ} 32^{\prime}-81^{\circ} 56^{\prime} \mathrm{W}$. Several mangrove systems with associated tidal flats occur in Coiba Island, two of which were selected for the present study: Santa Cruz and El Gambute. The first one is located within a cove on the NW coast of the island ( $7^{\circ} 37^{\prime} 30^{\prime \prime}$ $\mathrm{N}, 81^{\circ} 45^{\prime} 40^{\prime \prime} \mathrm{W}$ ) and, thus, it is under sheltered hydrodynamic conditions. The sediment is quite homogenously fine sand of moderate sorting throughout this large tidal flat and the presence of mangrove-derived tannins is evident from the red-brown color of interstitial water. The second one, much smaller, is located on the NE coast near Coiba Park Biological Station ( $\left.7^{\circ} 37^{\prime} 25^{\prime \prime} \mathrm{N}, 81^{\circ} 43^{\prime} \mathrm{W}\right)$. In this case, the sediment is mainly a poorly sorted mixture of muddy sand and pebbles, although patchy changes in sediment features can be observed.

Three transects were selected on each tidal flat and three sampling sites were arranged on each one. The lower one was located close to the low water line and the upper near the high water line, the third site (middle intertidal) was marked mid-way from the two others. Two samplings were carried out in each site, in February and in November of 1997. Each sample consisted of three replicates of $40 \mathrm{x}$ $40 \mathrm{~cm}$ square area and $30 \mathrm{~cm}$ sediment depth. They were sifted (1 mm gauge mesh) in the field and the obtained material was fixed and preserved in $10 \%$ formalin in seawater. Subsequently, it was separated from the remaining sediment and sorted into the higher taxonomic groups. Further information about the sampling sites and methodology is given in López et al. (2002). In the laboratory, the specimens were examined under a dissecting microscope and a light microscope with interference contrast optics (Nomarsky), both with an incorporated camera lucida. After the study, all specimens were preserved in $70 \%$ ethanol and the types were deposited in the Museo Nacional de Ciencias Naturales de Madrid (MNCN), Spain. For taxonomic descriptions, the character denominations proposed by Blake (2000) are used.

\section{RESULTS}

Orbinia Quatrefages, 1865

Orbinia oligopapillata n. sp.

Fig. 1-3

Material examined: Holotype. MNCN 16.01/8732A, northern side of Santa Cruz Beach, lower intertidal, fine sand, 15 Nov 1997. Paratypes. MNCN 16.01/8733, 14 specimens, middle of Santa Cruz Beach, lower intertidal, fine sand, 15 Nov 1997; MNCN 16.01/8732B, five specimens, northern side of Santa Cruz Beach, lower intertidal, fine sand, November 15 1997. Additional material. Three specimens, middle of El Gambute Beach, lower intertidal, medium sand, November 17 1997; three specimens, northern side of El Gambute Beach, middle intertidal, coarse sand, November 17, 1997.

Description: Holotype and paratypes are incomplete specimens. Holotype is the largest specimen; $0.8 \mathrm{~mm}$ wide at middle thorax, 0.6 $\mathrm{mm}$ wide at the beginning of the abdomen; $27 \mathrm{~mm}$ long, 81 chaetigers. Body yellowish in alcohol. Prostomium (Fig. 1A, B, 3A) sharp and divided in two regions; anterior one very narrow and small; posterior one clearly wider. Peristomium (Fig. 1A, B) very short and fused to first chaetiger, sharply widening to thorax width; lacking appreciable eyes but bearing lateral nuchal organs (Fig. 1A, 3A) on an anterior position. Mouth (Fig. 1A) ventral and extending to anterior end of first thoracic chaetiger; proboscis partially everted, striated. Thorax (Fig. 1A, B) consisting of the peristomium and 16 chaetigers (15 in some paratypes), slightly flattened in section. Notopodia as short low ridges on first two chaetigers (Fig. 1C); remaining thoracic chaetigers with a digitiform postchaetal lobe increasing in length on posterior 

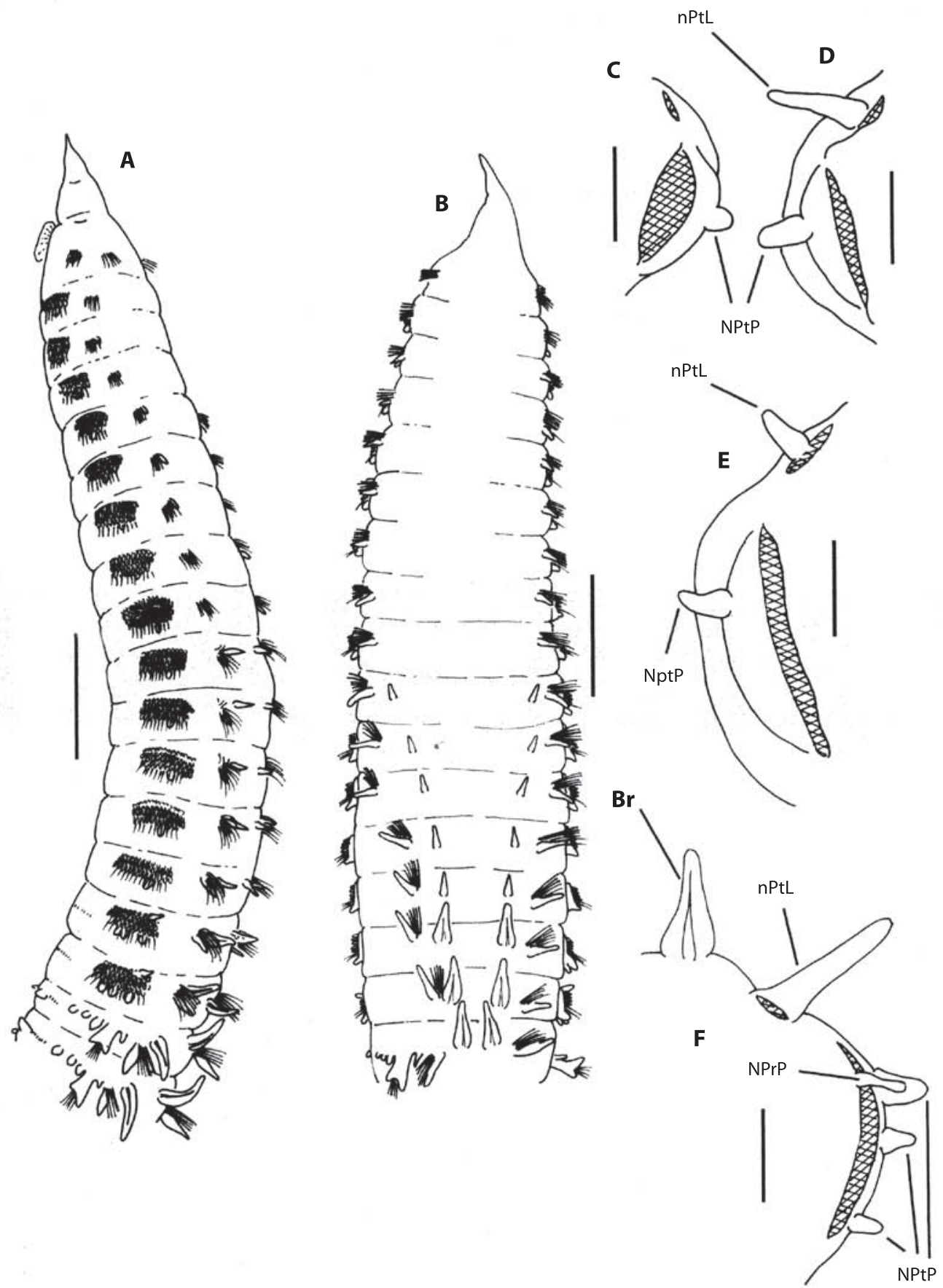

Fig. 1. O. oligopapillata n. sp., holotype. A. Anterior end, lateral view. B. Anterior end, dorsal view. C. Left parapodium, chaetiger two, anterior view, chaetae not drawn. D. Right parapodium, chaetiger six, anterior view, chaetae not drawn. E. Right parapodium, chaetiger 11, anterior view, chaetae not drawn. F. Right parapodium, chaetiger 15, anterior view, chaetae not drawn.- Hachured areas represent chaetae insertion places. Br. Branchia. NO. Nuchal organ. NPrP. Neuropodial prechaetal process. nPtL. Notopodial postchaetal lobe. NPtL. Neuropodial postchaetal lobe. NPtP. Neuropodial postchaetal process. SbPa. Subpodal papilla. STPa. Stomach papilla. Scale bar. A, B: 0.5 mm, C-F: $97.5 \mu \mathrm{m}$. 
thorax (Fig. 1D-F); bearing 13-15 crenulated, slightly curved capillaries. Neuropodia of first chaetiger as low transverse ridges, from chaetiger 2 to 14 (Fig. 1C-E) with a rounded postchaetal lobe bearing a papilliform process; last two thoracic chaetigers (Fig. 1F) similar in shape but bearing three papilliform postchaetal processes and a digitiform prechaetal process (Fig. 3D); with four or five rows of thick, curved uncini, numbering 50 on first chaetiger and increasing in number up to 70 ; those of anterior chaetigers (Fig. 2A, B, 3C) bearing transversal rows of minute spines and some with a longitudinal median groove; sculpture more indiscernible and median groove more distinct as more posterior the chaetiger (Fig. 2C, 3D); seven to 12 slender crenulated capillaries making a single row posterior to uncini. Abdomen incomplete, cylindrical in section. Anterior parapodial lobes located on sides, posteriorly achieving a more dorsal position. Notopodia with a long, lanceolate postchaetal lobe and a prechaetal lobe of increasing length towards posterior chaetigers (Fig. 2D, E); bearing about 30 crenulated capillaries in anterior abdomen and about 15 in median abdomen, furcated chaetae not seen; prechaetal lobe supported by one or two slightly sigmoid and protruding aciculae. Interramal cirri present on anterior-most abdominal chaetigers (Fig. 2D), progressively becoming less distinct (Fig. 2E) and disappearing. Neuropodia bilobed, with prechaetal lobe longer and supported by a stout, curved acicula (Fig. 2D, E); with about 5-10 crenulated capillaries and 3-7 flail-tipped chaetae (Fig. 2F, G); first two abdominal chaetigers with three piriform, large subpodial papillae (Fig. 2D); subpodial papillae progressively becoming less distinct to make a bilobed subpodial flange on median abdominal chaetigers (Fig. 2E). Stomach papillae only on first three abdominal chaetigers, piriform, numbering only up to eight (Fig. 1A, 3B). Branchiae erected, from chaetiger 10 (11 in some large paratypes); first five pairs (Fig. 1A, B) slender and cirriform or short and papilliform (might be retractile); remaining ones more stout and tapering to a short tip, somewhat longer than postchaetal lobe, bearing two dark glandular ridges but lacking fimbriation (Fig. 1F, 2D, E).

Etymology: The specific name refers to the number of stomach papillae which is much fewer than in other species of the genus.

Remarks: O. oligopapillata n. sp. is characterized by having 15-16 thoracic chaetigers with four or five rows of uncini and up to three papilliform postchaetal processes on neuropodial lobes, abdominal parapodia bearing flail-tipped neurochaetae and lacking furcated notochaetae, branchiae beginning on chaetiger 10 or 11 , interramal cirri, and a low number of subpodial and stomach papillae on anteriormost abdominal chaetigers.

Because of these features, it belongs to a distinct group of species characterized by the presence of subpodial papillae on first abdominal chaetigers, by a low number of stomach papillae on each segment and, in most cases, by having flail-tipped chaetae. Since in these species the number of stomach papillae is so clearly below the typical in the genus, they have been referred either to Scoloplos or to Orbinia. However, according to Blake (2000) all the species bearing stomach papillae and lacking modified spines on thoracic notopodia should be assigned to Orbinia and the type material of the species referred to Scoloplos should be carefully examined in order to evaluate the transfer of these species to Orbinia. This is far beyond the scope of the present work and these species are referred to by the name most widely used in the literature.

Orbinia hartmanae Day, 1977, from Australia (Day 1977), is the most similar species, with 12-21 thoracic chaetigers, branchiae from chaetiger eight, four rows of thoracic uncini, a similar number of postchaetal processes on thoracic neuropodia and of stomach papillae on first abdominal chaetigers, and flail-tipped chaetae. However, this species lacks a prechaetal process on thoracic neuropodia and interramal cirrus on abdominal chaetigers. Moreover, although the number of stomach papillae is also low, they occur in more chaetigers (last two in thorax and first six in abdomen). 

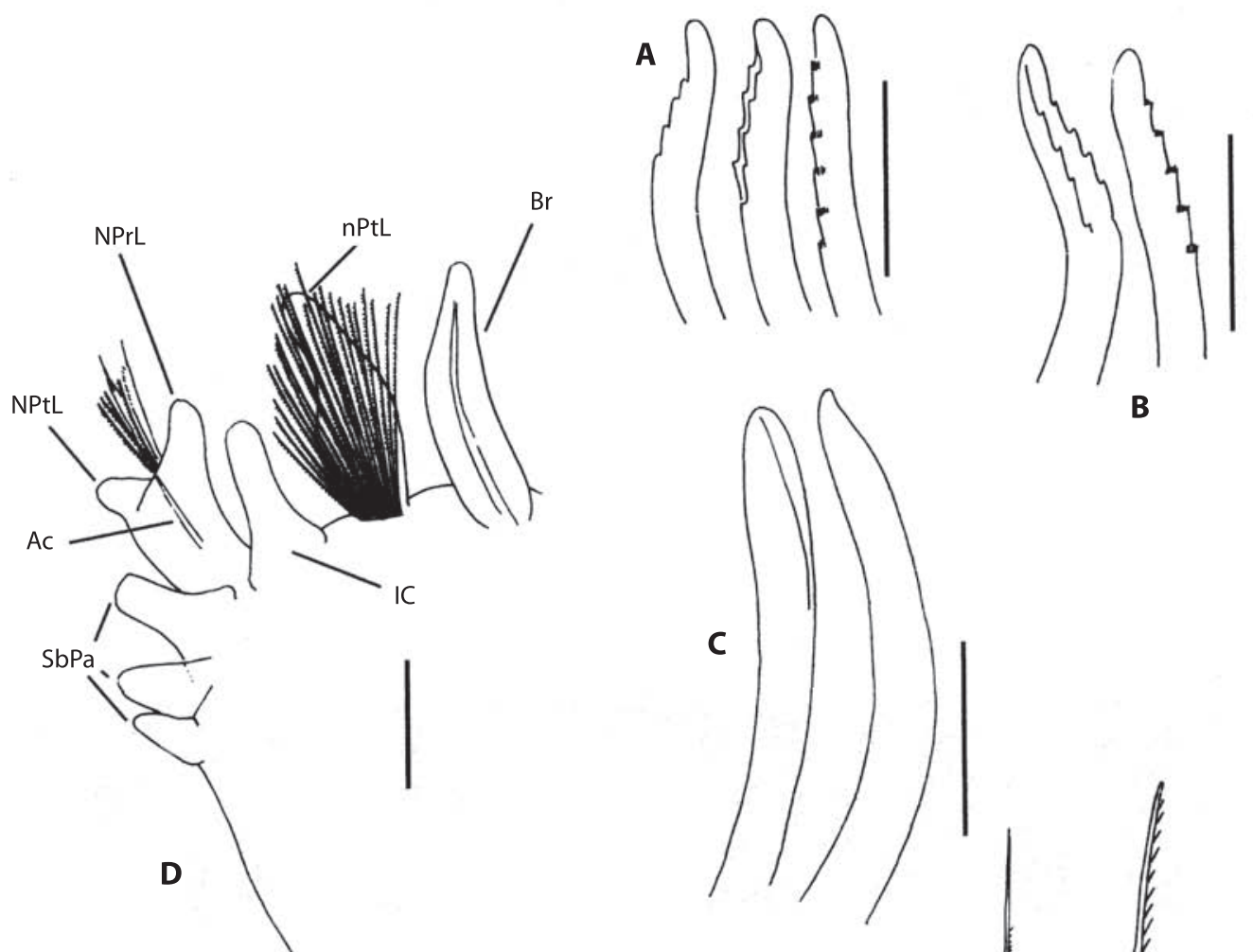

B

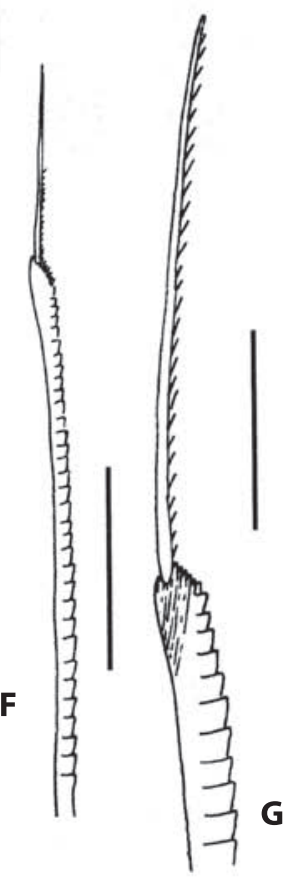

Fig. 2. O. oligopapillata n. sp., holotype. A. From left to right, anterior, median and posterior uncini, chaetiger two. B. From left to right, anterior and posterior uncini (thoracic neurochaetae), chaetiger six. C. From left to right, posterior and anterior uncini, chaetiger 11. D. Right parapodium, chaetiger 18, anterior view. E. Left parapodium, chaetiger 57, anterior view. F. Flail-tipped neurochaeta, chaetiger 57. G. Detail of the same. Ac. Acicula. Br. Branchia. IC. Interramal cirrus. nPrL. Notopodial prechaetal lobe. NPrL. Neuropodial prechaetal lobe. nPtL. Notopodial postchaetal lobe. NPtL. Neuropodial postchaetal lobe. SbPa. Subpodial papillae. SF. Subpodial flange. StPa. Stomach papillae. Scale bar. A-C, G: 20 m; D, E: $97.5 \mu \mathrm{m}$; F: $48 \mu \mathrm{m}$. 

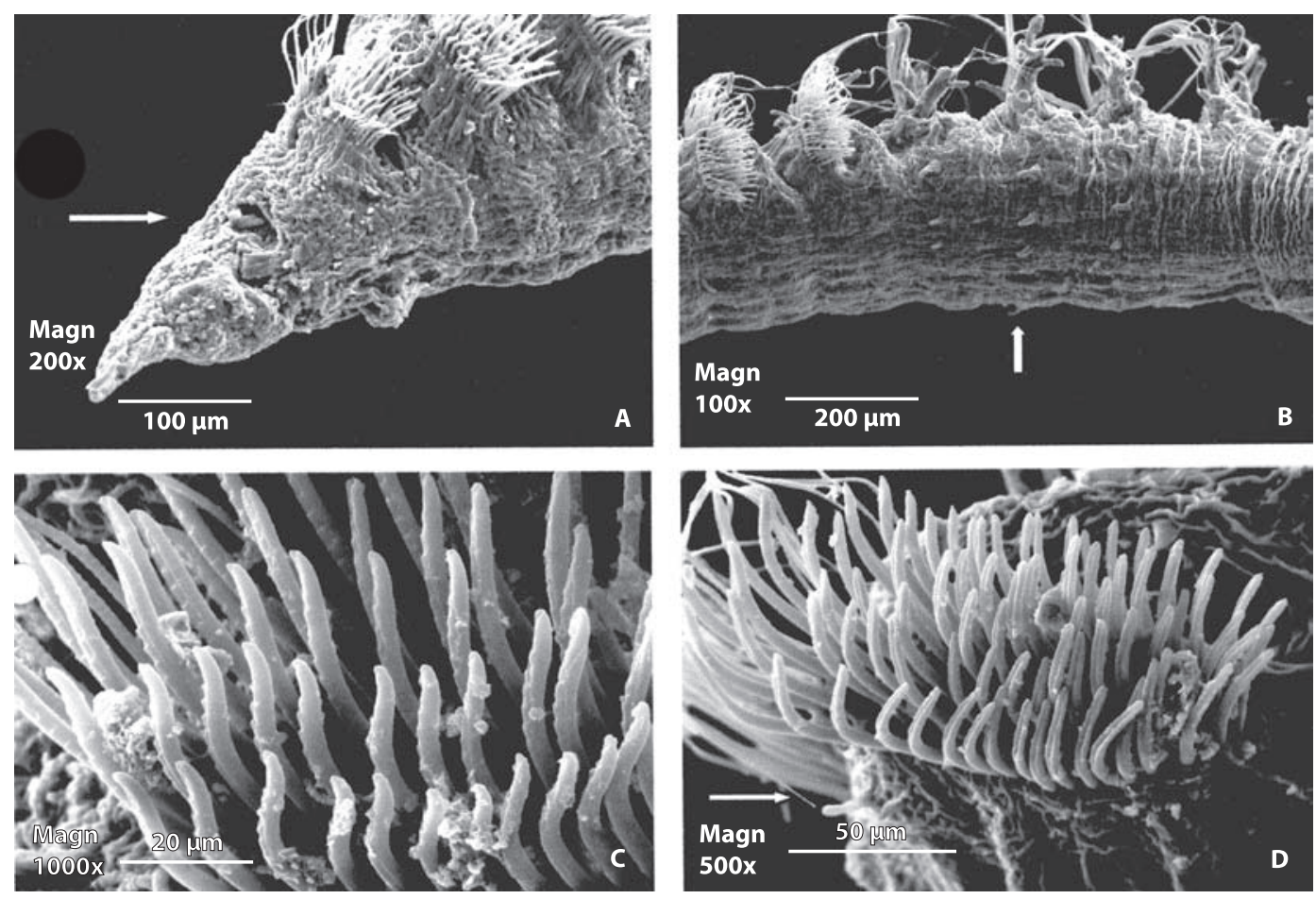

Fig. 3. SEM micrographs. O. oligopapillata n. sp. A. Anterior end, ventro-lateral view of left side showing nuchal organ (pointed by arrow). B. Anterior abdominal chaetigers, ventro-lateral view of left side showing subpodial and stomach papillae (pointed by arrow). C. Left neuropodial lobe, chaetiger three, showing uncini (thoracic neurochaetae). D. Left neuropodial lobe, chaetiger 15, showing uncini and prechaetal process (pointed by arrow).

Scoloplos (Leodamas) johnstonei Day, 1934 from Southern Africa and Australia (Day 1967, 1977), is a second species that also bears flail-tipped chaetae and a few subpodial and stomach papillae on first abdominal chaetigers, as well as thoracic neuropodia with four rows of uncini and one or two postchaetal processes, but it possesses 18-24 thoracic chaetigers, branchiae from chaetiger six onwards, and furcated notopodial chaetae on abdomen.

Orbinia riseri (Pettibone, 1957), from western Atlantic (Pettibone 1957, 1963, Day 1973, Taylor 1984), is similar to the new species in having branchiae that begin on chaetiger 8-10, thoracic neuropodia with four rows of uncini and 2-3 postchaetal processes, interramal cirri on abdominal neuropodia, and a low number of stomach papillae. On the other hand, it can be distinguished by lacking flail-tipped chaetae and by bearing many more chaetigers with stomach papillae (last six in thorax, first five in abdomen) and with interramal cirri (70 first abdominal chaetigers).

The last species of the group is $S$. (L.) fimbriatus Hartman, 1957, from Australia (Hartman 1957, Day 1977). It possesses thoracic neuropodia with four rows of uncini and several postchaetal processes and anterior abdominal neuropodia with interramal cirrus and two or three subpodial papillae; in addition, Day (1977) recorded the occurrence of a few stomach papillae, although they were not mentioned in the original description. This species can be distinguished from $O$. oligopapillata by the longer thorax (with 24 to 30 chaetigers), the branchiae beginning on chaetiger 7 , the presence of furcated chaetae and the lack of flail-tipped chaetae. 
Leitoscoloplos Day, 1977

Leitoscoloplos sp.

Fig. 4

Material examined: MNCN 16.01/8734, one specimen northern side of Santa Cruz Beach, upper intertidal, fine sand, February, 81997.

Description: Incomplete specimen; one anterior portion plus two abdominal fragments, the three fragments being apparently successive; $2.4 \mathrm{~mm}$ wide at middle thorax, $2.3 \mathrm{~mm}$ wide at anterior abdomen; anterior portion, first abdominal and second abdominal sections respectively $18 \mathrm{~mm}, 11 \mathrm{~mm}$ and 16 $\mathrm{mm}$ long, and with 41, 21 and 39 chaetigers. Body yellowish in alcohol. Prostomium (Fig. 4A, B) sharp and conical; peristomium (Fig. 4A, B) distinctly separated from prostomium but mid-ventrally, bearing a pair of lateral nuchal organs (Fig. 4B). Thorax consisting of the peristomium and 22 chaetigers, the last one being transitional; cylindrical in section; segments biannulated from the sixth. All thoracic parapodia biramous; thoracic postchaetal lobes of both rami inconspicuous. Notopodia with a small postchaetal lobe from chaetiger seven increasing in length on posterior chaetigers; bearing about 80 crenulated capillaries arranged in two or three rows. Neuropodia with a papilliform postchaetal process from chaetiger 7 (Fig. 4C), two processes from chaetiger 17 (Fig. 4D); with about 90 crenulated capillaries in three rows. Abdomen incomplete, cylindrical in section. Anterior abdominal parapodia with interramal cirri (Fig. 4E). Notopodia (Fig. $4 \mathrm{E}$ ) with long postchaetal lobe, fimbriated on upper side; bearing about 20 crenulated capillaries; without furcated chaetae. Neuropodia bilobed (Fig. 4E), with prechaetal lobe longer; with about 10 crenulated capillaries; subpodial flange with three ovate subpodial papillae (Fig. $4 \mathrm{E}$ ), developed posteriorly as thin, membranous lateral pouches from first abdominal chaetiger (Fig. 4B), wall of pouches clearly vascularized, vessels extending by notopodial and neuropodial lobes. Median posterior abdominal parapodia (Fig. 4F) with reduced pouches and without interramal cirri. Notopodia (Fig. 4F) with proportionately longer and more conspicuously fimbriated postchaetal lobe; bearing eight crenulated capillaries; without furcated chaetae. Neuropodia (Fig. 4F) bilobed, with both lobes long and separated, with six crenulated capillaries; subpodial flange with two clearly separated ovate papillae. Branchiae from chaetiger 23 (Fig. 4A, B); erected, first pair papilliform, gradually increasing in size; on anterior abdomen (Fig. 4E) slightly shorter than notopodial postchaetal lobe, bearing two dark glandular ridges but no fimbriation, tapering to a short tip; on posterior abdomen (Fig. 4F) similarly shaped but conspicuously fimbriated on both sides.

Remarks: The studied specimen of Leitoscoloplos sp. most likely belongs to an undescribed species but due to the variability of characters in the family a formal description based on a single specimen would be necessarily incomplete. It is characterized by having a large number of thoracic chaetigers (22), by possessing inconspicuous parapodial lobes in both rami of thorax, by having anterior abdominal lobes with interramal cirri and three subpodial papillae and by bearing branchiae from chaetiger 23. However, the most notorious characteristic of the specimen is the presence of lateral pouches on abdominal chaetigers. In the family Orbiniidae, this feature is present only in Scoloplos marsupialis Southern, 1921 and S. tumidus Mackie, 1991 (Mackie 1991), but the material from Coiba can readily be distinguished from them by the absence of neuropodial uncini on thorax. Although Day (1967) recorded juvenile specimens of $S$. marsupialis that lacked neuropodial uncini, the size of our specimen (too large to be a juvenile) prevents confusion.

Within genus Leitoscoloplos, the specimen can be placed in the last of the five groups stated by Mackie (1987). It is composed of species with numerous thoracic chaetigers and bearing interramal cirri and subpodial papillae: L. robustus (Verrill, 1873), L. fragilis (Verrill, 1873), L. panamensis (Monro, 1933) and L. obovatus Mackie, 1987. Apart of the lack of pouches, L. panamensis, from Pacific coast of Panama, and L. obovatus, from western 

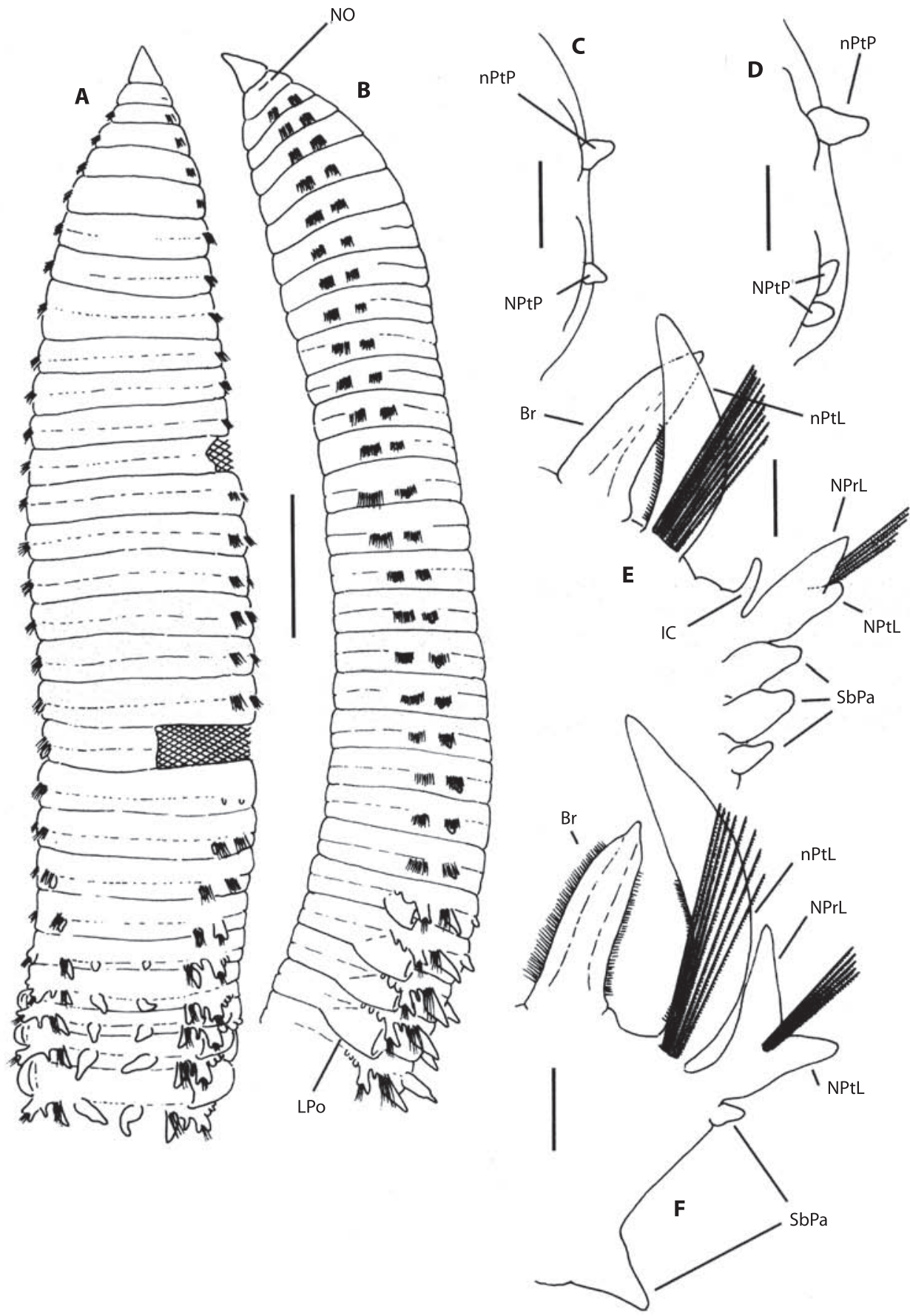

Fig. 4. Leitoscoloplos sp. A. Anterior end, dorsal view; hachured areas represent dissected portions. B. Anterior end, lateral view. C. Right parapodium, chaetiger 11, posterior view, chaetae not drawn. D. Right parapodium, chaetiger 19, posterior view, chaetae not drawn. E. Left parapodium, chaetiger 31, anterior view. F. Left parapodium, chaetiger 73, anterior view. Br. Branchia. IC. Interramal cirrus. LPo. Lateral pouch. NO. Nuchal organ. NPrL. Neuropodial prechaetal lobe. nPtL. Notopodial postchaetal lobe. NPtL. Neuropodial postchaetal lobe. NPtP. Neuropodial postchaetal process. SbPa. Subpodial papilla. Scale bar. A, B: $1.6 \mathrm{~mm}$; C-F: $0.2 \mathrm{~mm}$. 
Atlantic, further differ from Leitoscoloplos sp. in the shape of thoracic neuropodial lobes (mammiform in L. panamensis and triangular in $L$. obovatus, clearly projecting in the two species) as well as in the branchiae, which first occur on a more anterior chaetiger (11 in $L$. obovatus, nine in $L$. panamensis); also $L$. robustus, from Eastern Pacific, differs in having mammiform neuropodial lobes in thorax, albeit the first pair of branchiae appears on a quite posterior chaetiger (chaetiger 20-22). L. fragilis, from Western Atlantic, is the most similar species, having inconspicuous thoracic neuropodial lobes, but it has somewhat shorter thorax (up to 16 thoracic chaetiger according to Mackie 1987) and only two subpodial papillae on anterior abdomen.

\section{Naineris Blainville, 1828 Naineris sp.}

Fig. 5

Material examined: MNCN 16.01/8735, one specimen, middle of El Gambute Beach, lower intertidal, medium sand, February, 101997.

Description: Incomplete specimen. Medium sized specimen; $13.5 \mathrm{~mm}$ long for 57 chaetigers; $2.5 \mathrm{~mm}$ wide at middle thorax, $1.2 \mathrm{~mm}$ wide at first abdominal chaetigers. Body yellowish in alcohol with slightly dark dorsal bands on thorax; thoracic transversal ciliary rows not seen. Prostomium (Fig. 5A) broadly rounded and spatulate, without appreciable eyes or nuchal organs. Proboscis (Fig. 5A) partially everted, broad and irregularly lobed. Thorax (Fig. 5A) consisting of the peristomium and 40 chaetigers; dorso-ventrally flattened, rectangular in section, and distinctly expanded. Transition to abdomen is gradual between chaetigers 31 and 40. All thoracic parapodia biramous; first one similar to the remainder but smaller. Thoracic notopodia bearing a cirriform postchaetal lobe supported by a straight acicula and with a knob-like expansion near base (Fig. 5B, F); with 15-30 crenulated capillaries. Thoracic neuropodia (Fig. 5B, F) simple ridges, with a rounded postchaetal lobe bearing a distinct dorsal papilla from chaetiger four; with 5-6 rows of setae, numbering about 130 as a whole, all rows but one composed of geniculate capillaries (Fig. 5C, E), longer in the most posterior row; the row before the last consisting of about 15 heavy uncini grading from dorsal pointed spines to ventral blunted setae with distally open hoods (Fig. 5D); uncini and shafts of geniculate capillaries both bearing transversal ridges. Transition thoracic neuropodia bearing only geniculate capillaries (about 80 ) and spine-shaped uncini (about seven). Abdomen incomplete, near-cylindrical in section with flattened dorsum. Abdominal parapodia without interramal cirri. Notopodia (Fig. 5I) directed obliquely, with long postchaetal lobe bearing a cirriform dorsal process; bearing about 10 crenulated capillaries and 2-3 furcated chaetae (Fig. 5G), distal tines unequally long, shaft with rows of minute spines on the side of the shorter tine. Neuropodia (Fig. 5I) bilobed with prechaetal lobe shorter, supported by a protruding, sigmoid, distally rounded acicula (Fig. 5H); first abdominal neuropodia bearing a slender subpodial cirrus that gradually shortens until disappearing; about 10 crenulated capillaries, slightly thicker than notopodial ones. Branchiae from chaetiger 6 (Fig. 5A); bearing two dark glandular ridges but no fimbriation, compressed and tapering to a slender tip that lacks glandular material; first thoracic pair small, progressively increasing in length (Fig. 5F); abdominal branchiae (Fig. 5I) longer, darker and with proportionately longer tips.

Remarks: Although the specimen of Naineris sp. cannot be referred to any known species, the lacking of additional specimens from Coiba makes inappropriate to establish a formal description. It is characterized by its thoracic chaetiger number, branchiae, uncini, and bilobed abdominal neuropodia with protruding aciculae. To date, seven Naineris species have been recorded from the Pacific Ocean: N. berkeleyorum Pettibone, 1957, N. brevicephala Hartmann-Schröder, 1960, N. chilensis (Hartmann-Schröder, 1965), N. dendritica (Kinberg, 1867), N. grubei (Gravier, 1908), N. laevigata (Grube, 1855) and N. uncinata Hartman, 1957 (Hartman 1957, Pettibone 


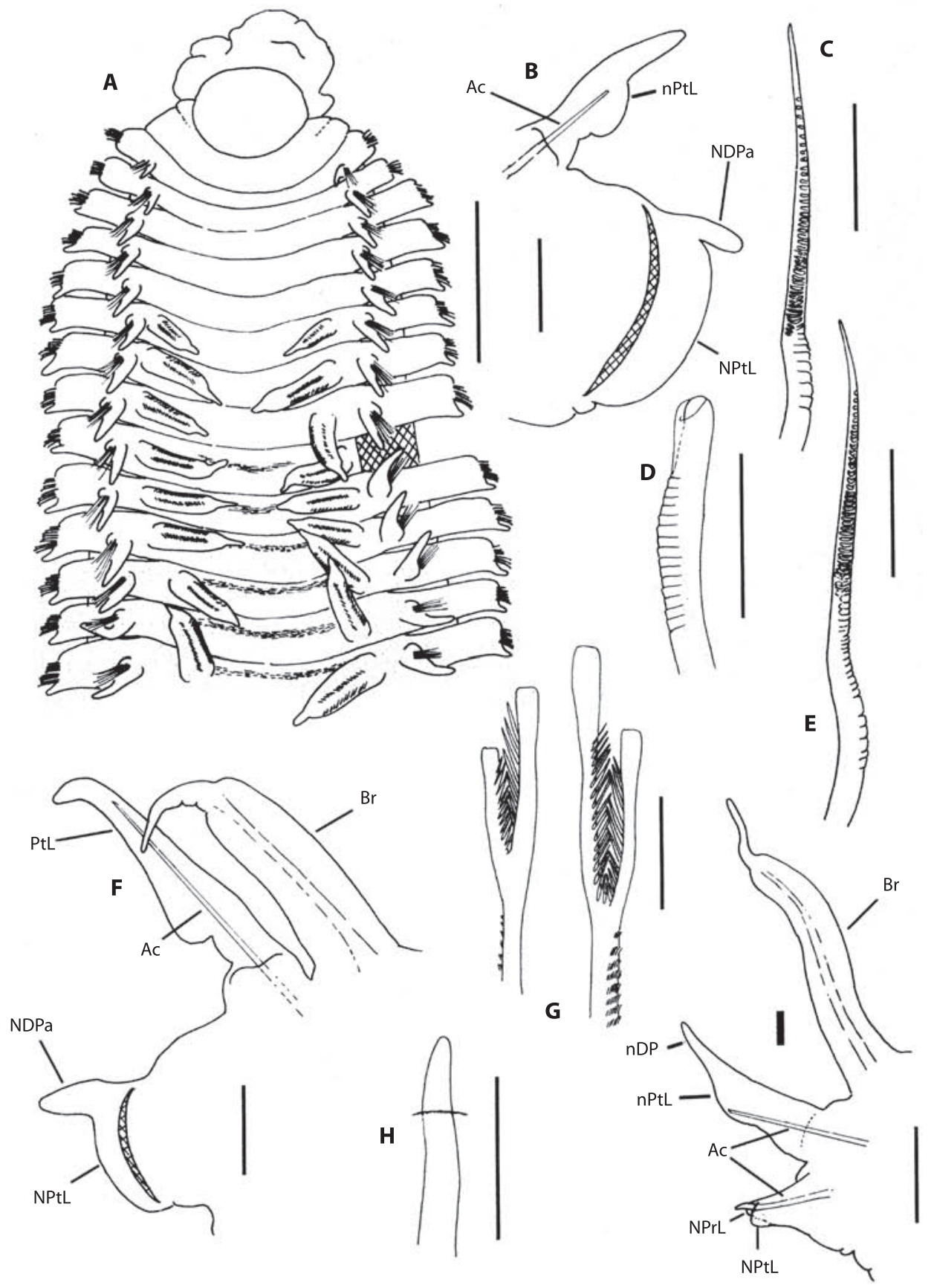

Fig. 5. Naineris sp. A. Anterior end, dorsal view; hachured area represents a dissected portion. B. Left parapodium, chaetiger four, anterior view, chaetae not drawn. C. Short geniculate neuropodial chaetae, same parapodium. D. Uncinus (thoracic neurochaeta), same parapodium. E. Long geniculate neuropodial chaetae, same parapodium. F. Left parapodium, chaetiger 36, posterior view, chaetae not drawn. G. Furcated chaetae, chaetiger 57. H. Acicula, same chaetiger. I. Left parapodium, same chaetiger, anterior view, chaetae not drawn. Ac. Acicula. Br. Branchia. nDP. Notopodial dorsal process. NDPa. Neuropodial dorsal papilla. NPrL. Neuropodial prechaetal lobe. nPtL. Notopodial postchaetal lobe. NPtL. Neuropodial postchaetal lobe. Scale bar. A: 1.6 mm; B, E, H: 0.2 mm; C, G: $48 \mu \mathrm{m}$; F: $20 \mu \mathrm{m}$. 
1957, Hartmann-Schröder 1960, 1965). All but $N$. chilensis and $N$. berkeleyorum have distinctly lower number of thoracic chaetigers. Naineris berkeleyorum differs from Naineris sp. in lacking transitional chaetigers and having thoracic neuropodial papillae in a ventral position, while Naineris chilensis (HartmannSchröder 1965, Carrasco 1977) differs in the in the lack of hood in uncini, the low number of neuropodial capillaries on thorax and the shape of abdominal neuropodial lobes, short and unilobed.

The two most similar species of the genus have been reported from the Gulf of Mexico and nearby regions. Naineris setosa (Verrill, 1900) and N. bicornis Hartman, 1951 closely resemble the specimen of Coiba in their general body form, very similar branchiae that start on chaetiger 6, thoracic neuropodia with dorsally located postchaetal papillae and bilobed abdominal neuropodia with protruding aciculae. However, $N$. setosa is unique within the genus in lacking any kind of uncini (Hartman 1951, Solis-Weiss and Fauchald 1989). Naineris bicornis is the most similar species, and the only differences are the bifid prostomium, the distinct fimbriation of branchiae and a slightly larger number of thoracic chaetigers, about 50, of which 10 form the transition region (Hartman 1951, Taylor 1984).

\section{ACKNOWLEDGMENTS}

The present work was performed within the framework of a research project financially supported by AECI (Agencia Española de Cooperación Internacional) and developed with the invaluable help of Panamanian INRENARE. The authors express their gratitude to the staff of Coiba National Park, especially to Narciso Bastida, Luis Jiménez, Cesar Pecchio and Iván Tuñón, who guided us all over the island coasts. Also our colleagues in the project staff (María Capa, Francisco García, Antonio Laborda and Elisa Roldán) are to be gratefully acknowledged for their inestimable collaboration, both in the field and in the laboratory tasks.

\section{RESUMEN}

En el Parque Nacional de Coiba, costa pacífica de Panamá, hay manglares con playas asociadas. Estudiamos la fauna de dos poliquetos orbínidos de Santa Cruz y El Gambute. En cada playa se eligieron puntos de muestreo al nivel de marea baja, media y alta y cada uno se realizaron dos muestreos, en febrero y noviembre de 1997. Encontramos individuos no identificables con certeza y una especie nueva: Orbinia oligopapillata n. sp., la cual se caracteriza por tener 15-16 setígeros torácicos con cuatro o cinco filas de uncinos y hasta tres procesos postsetales papiliformes en los lóbulos neuropodiales, por los parápodos abdominales provistos de sedas en bayoneta y por la presencia en los setígeros abdominales anteriores de papilas estomacales en escaso número. Leitoscoloplos sp. se caracteriza por llevar bolsillos laterales en los setígeros abdominales, caracter único en el género y que en la familia solo ha sido citada en dos especies del género Scoloplos. Naineris sp. se caracteriza por el número de setígeros torácicos, sus branquias, sus uncinos y sus neuropodios abdominales, bilobulados y con la acícula sobresaliente.

Palabras clave: mangle, planos de marea, este del Pacífico Tropical, Orbiniidae, poliquetos que cuidan sus huevos.

\section{REFERENCES}

Blake, J.A. 1996. Family Orbiniidae Hartman, 1942, p. 1-26. In J.A. Blake, B. Hilbig \& P.H. Scott (eds.). Taxonomic Atlas of the Benthic Fauna of Santa Maria Basin and Western Santa Barbara Channel. Volume 6. The Annelida Part 3. Polychaeta: Orbiniidae to Cossuridae. Santa Barbara Museum of Natural History, Santa Barbara, California, USA.

Blake, J.A. 2000. A new genus and species of polychaete worm (Family Orbiniidae) from methane seeps in the Gulf of Mexico, with a review of the systematics and phylogenetic interrelationships of the genera of Orbiniidae. Cah. Biol. Mar. 41: 435-449.

Capa, M., G. San Martín \& E. López. 2001a. Syllinae (Syllidae: Polychaeta) del Parque Nacional de Coiba, Panamá. Rev. Biol. Trop. 49: 103-115.

Capa, M., G. San Martín \& E. López. 2001b. Autolytinae, Eusyllinae y Exogoninae (Syllidae: Polychaeta) del Parque Nacional de Coiba, Panamá. Rev. Biol. Trop. 49: 621-628.

Carrasco, F. 1977. Polychaeta (Annelida) de Bahía de Concepción, Chile. Familias Orbiniidae, Cossuridae, Capitellidae y Ampharetidae, con la descripción de tres especies y una subespecie nuevas. Bol. Soc. Biol. Concepción 51: 67-92. 
Day, J.H. 1967. A Monograph on the Polychaeta of Southern Africa. Trustees of the British Museum (Natural History), London, England. 878 p.

Day, J.H. 1973. New Polychaeta from Beaufort, with a key to all species recorded from North Carolina. NOAA Technical Reports NMFS CIRC-375: 1-140

Day, J.H. 1977. A review of the Australian and New Zealand Orbiniidae (Annelida: Polychaeta), p. 217246. In D.J. Reish \& K. Fauchald (eds.). Essays on Polychaetous Annelids in Memory of Dr. Olga Hartman. Allan Hancock Found, Los Angeles, California, USA.

Fauchald, K. 1977. Polychaetes from intertidal areas in Panama, with a review of previous shallow water records. Smithson. Contr. Zool. 221:1-81.

Hartman, O. 1951. The Littoral Marine Annelids of the Gulf of Mexico. Publ. Inst. Mar. Sci. 2: 7-124.

Hartman, O. 1957. Orbiniidae, Apistobranchidae, Paraonidae and Longosomidae. Allan Hancock Pacific Exped. 15: 211-393.

Hartmann-Schröder, G. 1960. Zur Polychaeten-Fauna von Peru. Beitr. neotrop. Fauna 2: 1-44

Hartmann-Schröder, G. 1965. Zür Kenntnis des Sublitorals der chilenischen Küste unter besonderer Berücksichtigung des Polychaeten und Ostracodem. Teil II. Die Polychaeten des Sublitorals. Mitt. Hamb. Zool. Mus. Inst. 62: 57-169.

León-González, J.A. \& J.A Rodríguez. 1996. Orbiniidae (Polychaeta) from soft-bottom of the western coast of Baja California Peninsula, Mexico. Bull. Mar. Sci. 59: $169-174$

López, E., G. San Martín, P. Cladera \& M. Capa. 1997. La fauna de Anélidos Poliquetos del Parque Nacional de Coiba (Panama), p. 57-73. In S. Castroviejo (ed.). Flora y Fauna del Parque Nacional de Coiba (Panama). AECI, Madrid, Spain.

López, E., P. Cladera, G. San Martín, A. Laborda \& M.T. Aguado. 2002. Polychaete assemblages inhabiting intertidal soft bottoms associated to mangrove systems from Coiba National Park (East Pacific, Panama). Wetlands Ecol. Manag. 10: 233-242.

López, E., P. Cladera \& G. San Martín. 2003. Two new species of the genus Leodamas (Orbiniidae: Scolecida: Polychaeta) from the Pacific coast of Panama. J. Mar. Biol. Ass. U.K. 83: 367-374.

Mackie, A.S.Y. 1987. A review of species currently assigned to the genus Leitoscoloplos Day, 1977 (Polychaeta: Orbiniidae), with descriptions of species newly referred to Scoloplos Blainville, 1828. Sarsia 72: 1-28.

Mackie, A.S.Y. 1991. A new species of Scoloplos (Polychaeta: Orbiniidae) from Hong Kong and a comparison with the closely related Scoloplos marsupialis Southern, 1921 from India. Asian Mar. Biol. 8: 35-44.

Pettibone, M.H. 1957. North American genera of the family Orbiniidae (Annelida: Polychaeta), with descriptions of new species. J. Wash. Acad. Sci. 47: 159-167.

Pettibone, M.H. 1963. Marine polychaete worms of the New England region. I. Aphroditidae through Trochochaetidae. Bull. U.S. Nat. Mus. 227: 1-356.

San Martín, G., E. López, M.S. Redondo, M. Capa, P. Cladera \& A. Laborda. 1997. El bentos marino del Parque Nacional de Coiba (Panama), p. 33-55. In S. Castroviejo (ed.). Flora y Fauna del Parque Nacional de Coiba (Panama). AECI, Madrid, Spain.

Salazar-Vallejo, S., J.A. de León-González \& H. SalaicesPolanco. 1988. Poliquetos (Annelida: Polychaeta) de México. Libros Universitarios, Universidad Autónoma de Baja California Sur, La Paz, Mexico. 212 p.

Solis-Weiss, V. \& K. Fauchald. 1989. Orbiniidae (Annelida: Polychaeta) from mangrove root-mats in Belize, with a revision of the protoariciin genera. Proc. Biol. Soc. Wash. 102: 772-792.

Taylor, J.L. 1984. Family Orbiniidae Hartman, 1942, p. 1-38. In J.M. Uebelacker \& P.G. Johnson (eds.). Taxonomic Guide to the Polychaetes of the Northern Gulf of Mexico. Vol. I. Barry A. Vittor, Mobile, Alabama, USA. 